\title{
Increasing the Angle of Educational Reform in Pakistan through Professional Development
}

\author{
Nilofar Vazir \\ Aga Khan University Institute for Educational Development
}

Alan Wheeler

Brock University

\begin{abstract}
This paper documents the development of a "grassroots" teacher professional development model from Pakistan and region designed around three critical aspects: (a) the impact on classroom teaching and learning, (b) the provision for capacity building, and (c) a mechanism for ongoing support and sustainability. The development and evolution of the innovation is presented in terms of three stages designed to increase the angle of educational reform through total school improvement. The implications of the model as a promising prototype are discussed in relation to the wider professional development needs of teachers in the developing world.
\end{abstract}

Frequently mentioned global concerns within teacher education include the effectiveness of in-service education, governance, professionalism, and the need to develop sound indigenous models of teacher education. A prevalent issue embedded in the above concerns involves the nature of the "UniversitySchool" relationship on an ongoing basis (Smedley, 2001). Any effective professional development partnership must therefore directly address all these prevalent issues, while, in addition, incorporate important cross-cultural variables essential to effective teaching and learning (Kanu, 2000).

The Aga Khan University Institute for Educational Development (AKU-IED) was established in Karachi in 1993 in the context of a continued and deepening decline in the quality of education systems in Pakistan and elsewhere in the developing world. Key education indicators illustrated the poor quality of education; low and inequitable enrolment and retention rates; irrelevant curricula compounded by ineffective assessment curricula which in turn

Nilofar Vazir is currently a Senior Instructor at the Aga Khan University Institute for Educational Development (AKU-IED) in Karachi, Pakistan. Dr Vazir recently completed her $\mathrm{PhD}$ in Teacher Education from the Ontario Institute for Studies in Education, University of Toronto, Canada in 2003. Alan Wheeler is a Professor at Brock University with an interest in international and comparative education. During the period 1995-2000 he served as Academic Director for AKU-IED while on official leave from Brock University. 
fostered rote learning and passive student roles; and poorly resourced schools staffed by inadequately trained and supported teachers (Report of the Chancellor's Commission, 1994).

\section{Teacher Education in Pakistan}

Like many developing countries, Pakistan faces enormous developmental and social problems. Predictably, many of these challenges are deeply reflected in the field of education and constituted the context and backdrop for the Teacher Education inservice initiative presented here.

Contributing to and exacerbating these problems are the lack of adequate expenditure on all aspects of education and the low status accorded teachers. Teacher performance is severely handicapped by an insufficient number of teachers to keep pace with the growing numbers of children, often resulting in unmanageable large classes. Other factors include the poor quality of initial teacher education, poor supervision with little attention to performance in the classroom, and a chronic shortage of teachers in rural schools. The curriculum often lacks relevance, and teaching and learning strategies are largely shaped by ineffective testing and an examination system which fosters rote learning and passive student roles.

The educational scenario described above applies, in varying degrees, across the developing region served by Aga Khan University Institute for Educational Development (AKU IED), namely South Asia (Pakistan, India, Bangladesh), Central Asia (Tajikistan, Kyrgyzstan), and East Africa (Tanzania, Uganda, Kenya).

Pakistan offers two main kinds of teacher training: pre-service training in colleges or universities and inservice courses. Pre-service leads to credentials such as the Primary Teaching Certificate (PTC), the minimum qualification for trained primary school teachers; the Certificate of Teaching (CT), required for middle school teachers; and the Bachelor of Education (B.Ed.) for qualified high school teachers. Access to inservice education is severely limited and where available is offered on an ad hoc, individual basis. Courses are typically of short duration, usually lasting between one to three days. More importantly, there is no demonstrable relationship between the inservice component and the resulting quality of classroom teaching and student learning. Moreover, the dominant approach to inservice education takes place in isolation to other stakeholders and does not allow for collaboration with school heads and other colleagues.

Not surprisingly therefore teacher education has made little or no impact on the quality of classroom teaching and student achievement. In fact, 
previous studies on both pre-service and inservice education in Pakistan, Nauman, H. (1990) and Warwick \& Reimers, (1995) have shown these programs have had marginal effects on teacher behaviour and student learning. Hence, teachers who completed further training continued to teach in the same teachercentered, rote learning manner that their childhood teachers had used and hence the cycle continues.

This unsatisfactory existing situation necessitated a program that would address the teachers' needs, preparing them to reflect on their current practice, acquire new skills and strategies and apply these in their own context to aid their personal and professional development. These 'reprofessionalized' teachers would then be in a better position to bring about a meaningful change in their own classrooms and in their school (Fullan, 1995). The reprofessionalization model presented here is consistent with the work of John Furlong et al, (2000) who focus on the importance of engaging those involved in professional development in the reconceptualization of teaching and learning over a significant period of time.

\section{Increasing the Angle of Reform through Professional Development}

The early work of Beeby (1966) on the development of educational systems in developing countries following independence remains a valid theoretical framework to examine factors which influence the quality of education in less developed countries today. Beeby's model is characterized by four stages (Dame Schools, Formalism, Transition, and Meaning) as shown in Figure 1. As an educational system evolves from stage to stage, schools become less rigid in terms of the degree of external control exercised on them, teachers become less autocratic in their style, discipline less authoritarian and extrinsic in nature, and the curriculum and textbooks far less prescriptive. As a result, classrooms become increasingly more student-centered, student learning more meaningful, and the school more selfdirected.

Beeby viewed an educational system's progression through the four stages as essentially sequential and evolutionary in nature. That is:

There are certain stages of growth which all school systems must pass; although a system may be helped to speed up its progress, it cannot leapfrog a stage or major portion of a stage. 
Table 1

Beeby's Developmental Model - Stages in the Growth of a Primary School System

\begin{tabular}{|c|c|c|}
\hline (1) Stage & (2) Teschers & (3) Characteristics \\
\hline 1. Dame School & Ill-educated, untrained & $\begin{array}{l}\text { Unorganized, relatively meaningless symbols; very } \\
\text { narrow Subject coetent - } 3 \text { R's; very low standards; } \\
\text { memorizing all important. }\end{array}$ \\
\hline 2. Formalism & IIl-educated, trained & $\begin{array}{l}\text { Highly organized; symbols with limited meaning; rigid } \\
\text { syllabus; emphasis on } 3 \mathrm{R} \text { 's; rigid methods - cone best } \\
\text { way'; one textbook; extemal examinations; inspection } \\
\text { stressed; discipline tight and external; memorizing heavily } \\
\text { stressed emotional life largely ignored. }\end{array}$ \\
\hline 3. Transition & Better-educated, trained & $\begin{array}{l}\text { Roughly same goals as stage 2, but more efficiently } \\
\text { achieved; more emphasis on meaning, beat still nather } \\
\text { 'thin' and formal; syllabus and textbooks less restrictive, } \\
\text { but teachers hesitate to use gremer freedom; final leaving } \\
\text { examination often restricts experimentation; little in } \\
\text { elassfoom to eaner for the emotional and ereative life of a } \\
\text { child. }\end{array}$ \\
\hline 4. Meaning & Well-educated, trained & $\begin{array}{l}\text { Meaning and understanding stressed; wider cumiculum, } \\
\text { varicty of content and methods; individual differences } \\
\text { eatered for; activity methods, problem solving and } \\
\text { creativity; internal tests; relaxed and positive discipline; } \\
\text { emotional and aesthetic life, as well as intellectual; closer } \\
\text { relations with community; better buildings and equipment } \\
\text { essential. }\end{array}$ \\
\hline
\end{tabular}

Many LDCs attempt to bridge the development gap by omitting an intermediate stage without due attention to the necessary investment in human capital required to bring about the change, namely the increased quality achieved through the continuous professional development of the classroom teacher. Beeby strongly contended that the significant driving force behind the capacity of developing educational systems to move from one stage to the next higher one was the quality of the teachers in the system. This refers to both the quality of initial teacher training and the provision of ongoing professional development.

In general, as an educational system evolves from stage to stage, schools become less rigid in terms of the degree of external control exercised on them, teachers become less autocratic in their style, discipline less authoritarian and extrinsic in nature, and the curriculum and textbook less prescriptive. As a result, classrooms become increasingly more student-centered, student learning more meaningful, and the schools more self-directed. 
Teachers in the context of the developing world generally have far less formal education and provision for continued professional growth than in the developed world. Beeby's model highlights the pivotal role played by the classroom teacher as a change agent in educational development and the importance of teacher education in national development. Since future teacher professional growth over one's teaching career is highly dependent upon one's initial position in Beebe's model, the probability of significant change being brought about through traditional professional inservice programs for teachers is severely limited.

For significant impact to occur, inservice education in developing countries must be carefully designed in accordance with the contextual and professional needs of the teachers involved (Hoyle and John, 1995).

Under Beeby's Model, it is possible to increase the quality of teaching and learning through the provision of relevant, ongoing inservice teacher education provided key components and support mechanisms are in place. Such efforts result in what Beeby termed an increased 'angle of reform' in teacher education whereby the amount of professional growth over a given teacher's career can be greatly enhanced through meaningful professional development on a sustained basis. Efforts to create too acute an angle of reform (i.e., dramatic change) are unrealistic and doomed to failure, while if the angle is minimal, little or no professional development occurs and the system simply stagnates. This is often the case where the inservice input is limited in duration and lacks any follow-up component.

A key to effective inservice education in the developing world therefore is to carefully match the program to the incoming level and contextual needs of the teachers involved to achieve an appropriate angle of reform. With ongoing support over sufficient time, professional development efforts are capable of achieving a significant angle of reform in Teacher Education in the realities of the developing world.

\section{The Aga Khan University Institute for Educational Development (AKU-IED)}

The teacher education school improvement model implemented by the Aga Khan University's Institute for Educational Development (AKU-IED) was guided by three principles: (a) field-based, on the job learning; (b) helping teachers to become reflective practitioners; and (c) training in classroom-based research. These principles are in accordance with key elements in teacher education which foster professionalism : namely; knowledge, autonomy, and responsibility (Hoyle and John, 1995).

The first M.Ed. program started in early January 1994 with 23 course participants. Upon completion of the M.Ed. program, the graduates returned to their 
home schools throughout the region to serve as Professional Development Teachers (PDTs) and their home schools became AKU-IED's first cooperating schools. Upon re-entry, the PDTs were expected to foster the professional development process in their respective schools with teachers, while also serving as instructors in a 'grassroots' professional development program called the Visiting Teacher Program (VTP). To more accurately reflect the more generic and evolving nature of the Visiting Teacher Program this initiative was renamed the Certificate in Teacher Education (CTE) Program in 2002. The CTE Program was designed on the basis of two main principles: (a) that teachers can function as effective professional developers, planning and facilitating services with colleagues as well as teaching in their own classroom, and (b), that teachers should become reflective practitioners through maintaining reflective journals, fostering action research in their classrooms and by constructing new knowledge based upon their existing knowledge.

From the onset, there was a strong symbiotic relationship established between the PDTs and teachers enrolled in the CTE Program as the PDTs were substantially involved in the planning, instruction and evaluation of the initial courses. In addition, AKU-IED faculty members worked closely with the PDTs and performed a key advisory and consultative role in the evolution of the CTE Program. Following the conclusion of each CTE course, those PDTs involved in the delivery of the program returned to their home schools where they continued to work with many of the graduates of the program who held regular classroom teaching responsibilities in the same cooperating schools. It was this regular, ongoing professional interplay and feedback provision between AKUIED faculty, the Professional Development Teachers and other program graduates, which represents a powerful feature of the overall educational change strategy being implemented. The specifics of the Change Model designed to reconceptualize teacher education at AKU-IED are described more fully by Wheeler (2000).

\section{Evolution of the Certificate in Education Program}

The Certificate in Education (CTE) Program was an integral 'grassroots' component of the overall change strategy at the classroom level. An examination of the changes that took place since the inception of the program reveals that a distinguishing feature of the program has been the strong evolutionary process that characterized its progress over the years. While this process proceeded in an incremental fashion, the overall effort has been substantial. The development and evolution of the CTE Program can be described in terms of three distinct stages. 
Educational Reform in Pakistan

\section{Stage 1: Initial Development and Implementation (October 1995-August 1996)}

This formative period saw the initial development, implementation and evaluation of the first round of the CTE Program. It was characterized by considerable planning by AKU-IED faculty and Partner University Faculty from Oxford University and the Ontario Institute for Studies in Education (OISE/UT) together with designated teams of the newly graduated Professional Development Teachers from the first M.Ed. cohort (1994-1995). While the conceptualization for the Certificate in Education Program was laid out by the First Task Force Report (1991), the actual specifics of scope, sequence and content of the individual programs were not dealt with. Initial plans called for four offerings during this Stage with a total of 20 candidates in each subject area (Social Studies, English, Mathematics, and Science) drawn from AKUIED's cooperating schools in Karachi. The initial cycle did not contain a focus in Primary Education.

Eight lessons were learned during Stage 1. Specifically, these were that:

- the program proved too comprehensive in scope,

- the program needed an extension for selected individuals,

- more content emphasis was needed,

- a school follow-up was essential,

- the program should be bilingual,

- other subject areas should be added,

- 're-entry' skills for participants should be addressed, and lastly,

- the program should be more regionally based.

While the original enrolment for the first offering was projected to be 80 candidates, the actual number graduating was 125 , more than one-third more than predicted. It was felt that, if future offerings were going to address the professional development needs of the region served by AKU-IED, all lessons acquired from experiences during this important initial phase should be fully integrated into future offerings.

\section{Stage 2: Revision and Consolidation Stage (September 1996 - June 1998)}

This period saw a rapid build-up of the number of candidates enrolled in the CTE Program and the implementation of several significant changes in the nature and focus of the program consistent with the eight lessons acquired in Stage 1 as noted above. For example, Primary Education was added as a separate CTE course and a contextually relevant CTE Program, in Urdu, was designed and delivered for 
candidates from selected districts in the neighboring Province of Balochistan following a request by Government Officials. This encouraging initiative required the CTE Program to better accommodate to the realities of education in a rural context and further reinforced the resiliency and flexibility inherent in the design of the CTE program.

In addition, Stage 2 saw a substantial reduction in the instructional involvement of AKU-IED and Partner University faculty members as a consequence of the increased confidence and experience acquired by the specialist teams of PDTs. That is, faculty members assumed more of a coordinating and organizational role for each offering while the PDTs took on the major responsibility for the planning, delivery and evaluation of the program. The significant involvement in the delivery of the CTE by the experienced teams of PDTs is highly desirable according to Boston (1997), whereby the professional development of newer teachers is facilitated by the direct and regular interaction with more experienced and qualified teacher educators like the PDTs. In this sense the model reflects a 'teacher-teaching-teacher' approach.

Stage 2 also saw an increased demand by international candidates to enroll in the CTE Program, most notably from East Africa, Bangladesh and later India. In general, Stage 2 was both a period of considerable revision and consolidation.

\section{Stage 3: Regionalization and Transformational Stage (July 1998 - 2004)}

Stage 3 proved to be a truly dynamic period as it includes both the transferability of the CTE Program to contexts outside of Karachi and the rigorous testing of alternate delivery modes for the program. Consistent with the need to initiate capacity building in professional development in the region, a special offering was delivered for East African candidates in August 1998. The so-called 'Nairobi Model' represented the first off-shore offering of the Program. This was followed by several international offerings including in 1999-2000 a 'Dhaka Model' in Bangladesh, further initiatives in East Africa and Central Asia and a major thrust to meet the ongoing professional needs of teachers in the northern parts of Pakistan following the completion of the Professional Development Centres in Gilgit and Chitral.

Stage 3 was a period of experimentation with alternate delivery modes for the CTE Program based on the considerable feedback gained during the implementation of offerings in earlier stages in Karachi. This included an expressed need to consider an alternate to the full time, eight-week structure associated with Stages One and Two to allow candidates a field-based component whereby they could try out the pedagogical skills acquired in their own classroom on a longer term basis. The Nairobi Model represented the first alternate mode of the CTE Program as it consisted of a three-week module conducted during the school break, a three- 
month practicum period in the candidates' home schools and a concluding on-site module. As a result of the positive evaluation of the Nairobi Model, a pilot schoolbased CTE Program was implemented in Karachi in December 1999 whereby candidates implemented many of the ideas introduced in the initial component in their own classrooms under close supervision and support by their PDTs and AKUIED faculty members.

More impressive than any quantitative pay-off of the model however, were the qualitative indicators of increased learning and achievement that were becoming evident in the cooperating schools where AKU-IED's graduates were involved in systematic and systemic school improvement. This qualitative aspect is evident in a series of case studies undertaken on the changes in selected cooperating schools in the region since the intervention commenced (Vazir, 1998). Many schools had established a school improvement team consisting of one or more Professional Development Teachers, a School Head who had graduated from the educational management program at AKU-IED, and a number of certified graduate teachers. The case studies involved extensive classroom observation and interviewing and examined ways in which the stakeholders had reconceptualized their thinking through reflective practice and by the construction of new knowledge. Classroom observations were analyzed to ascertain how the teachers' thinking had influenced and affected their actions in the classroom and in their school.

All graduate teachers felt that the reprofessionalization program had enabled them to apply the constructivist philosophy of learning and teaching in their classroom. Each Certified Teacher, in her own way, had contributed to the following components: improved unit planning; reflective writing (problem-solving and constructive feedback); new techniques of teaching (e.g. demonstration, discussion, brainstorming, mind mapping); new learning strategies (e.g. cooperative learning/activity-based learning); improved social skills; effective ways of preparing low cost resource teaching aids and material, and improved skills in conducting workshops (Vazir, 1998).

Many participants expressed how important it was for them to continue to practice reflective journal writing and maintained that reflective practice helped them to develop their thinking skills, critically and creatively. Journal writing served to check their own understanding and conceptual knowledge, as well as to develop further understanding of how students learn.

Discussions with the teachers revealed that the professional development program had brought about a change in their thinking as they no longer depended on textbooks for teaching but rather used their prior knowledge and constructed new knowledge. They had also begun to incorporate elements from the research literature into their practice. 
The contextualization and transformation of the professional development model will undoubtedly continue in ways in accordance with emerging needs of the region. Currently, for example, a viable Total School Improvement Model in selected partner schools associated with the new Professional Development Centres in northern Pakistan has met with encouraging results with numerous other initiatives to contextualize the Certificate in Teacher Education planned for the future. Since its inception many new approaches have been incorporated keeping in view contextual realities and needs of the diverse population of teachers AKU-IED serves. These have included for example; Certificate in Education Programs in the areas of Health Education; Inclusive Education; Early Childhood Education; and Educational Leadership and Management.

\section{Conclusion}

A distinguishing feature of the CTE Program is evident in the built-in 'multiplier effect' associated with the approach taken. This is shown in Figure 1 below where by the end of 2004, the change model had developed 210 PDTs who worked directly with 3443 Certified Teachers.

\section{Figure 1}

Potential Multiplier Effect (Direct/Indirect) of the Professional Development Teachers (PDTs) $(n=115)$

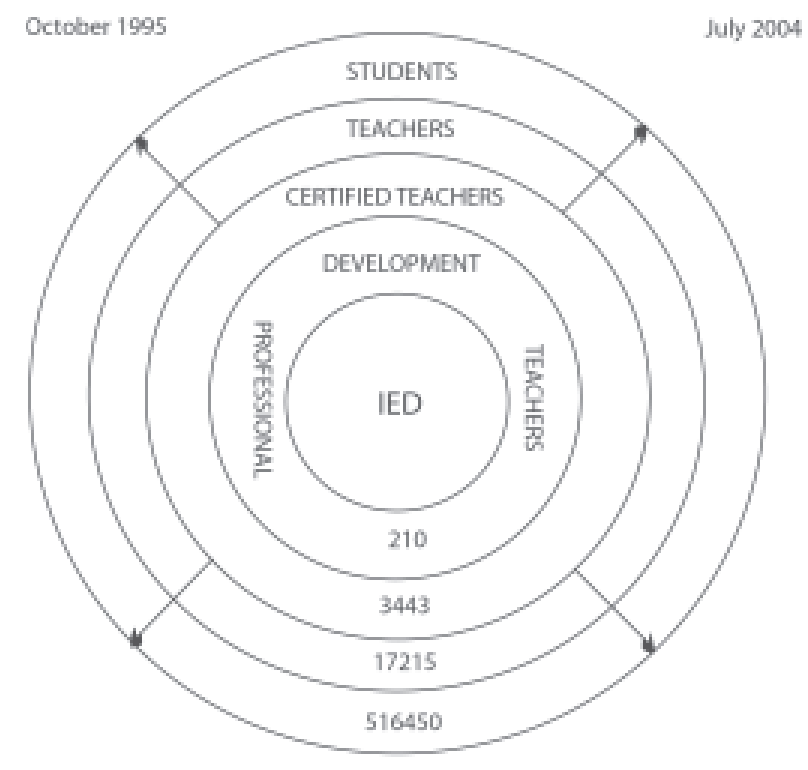


Using a critical mass analogy, this multiplier effect was based on the estimation that each returning graduate certified teacher would significantly influence at least five colleagues throughout his or her teaching career. Hence, the number of teachers directly or indirectly impacted by AKU-IED's efforts in the longer term constituted a five-fold increase. Using a conservative estimate of 30 students per class, the overall influence of these efforts indirectly impacted on the learning of a substantial number of classroom students in the cooperating schools.

The overall target in this school improvement initiative was the total involvement of each cooperating school in the improvement of the quality of classroom teaching and learning. That is, the unit of development was the school itself as a whole, not on any given individual or individuals in the system.

The key to any successful educational change initiative lies in the ability to build upon the strengths of the endeavor and to incorporate all relevant modifications for replicating the process according to the evolving needs and contexts of the targeted population. The evolution of the Certificate in Teacher Education (CTE) Program as documented here, is no exception to this principle. It lies at the heart of the overall professional development change model being implemented in the region and reflects a viable 'grassroots' approach which has shown to have exceptional resiliency and application in a variety of contexts. In many ways, it reflects the basic principles of sound educational reform by placing a priority on the centrality of the classroom teacher.

\section{References}

Beeby, C. E. (1966). The quality of education in developing countries. Cambridge, MA: Harvard University Press.

Boston, J. A. (1997). Professional development in global education. In M. M. Merryfield, E. Jarchow, \& S. Picket (Eds.), Preparing teachers to teach global perspectives: A handbook for teacher educators (pp. 168-187). US: Corwin Press Inc.

Brint, S. (1998). Schools and societies. UK: Sage Publications Ltd.

Crossley, M. (1984). Strategies for curriculum change and the question of international transfer. Journal of Curriculum Studies, 16(1), 75-88.

Fullan, M. (1995). The new meaning of educational change. London: The Falmer Press.

Furlong, J., Barton, L., Miles, S., Whiting, C., \& Whitty, G. (2000). Teacher education in transition: Reforming professionalism? Great Britain: St. Edmundsbury Press Ltd. 
Hoyle, E. \& John P. (1995). Professional knowledge and professional practice. London: Cassell.

Nauman, H. (1990). Primary teaching certificate program in N.W. F. P.: A study. Cambridge, MA: Project BRIDGES. Harvard Institute for International Development, Harvard University.

Kanu, Y. (2000). Curriculum, culture and teacher learning: A case study of an innovative teacher education program in Pakistan. Canadian and International Education, 29(2), 21-45.

Report of the Chancellor's Commission (1994, Nov.). The future of Aga Khan University: Evolution of a vision ( pp. 135).

Schon, D. (1997). Educating the reflective practitioner. San Francisco: JosseyBass.

Smedley, L. (2001). Impediments to partnership: A literature review of schooluniversity links. Teachers and Teaching: Theory and Practice, 7(2), 189-208.

The Aga Khan University Institute for Educational Development (1991). A proposal to the Board of Trustees (pp. 43).

Vazir, N. (1998). The Impact of IED's Visiting Teacher Programme: Case study of a co-operating school in transition. Unpublished M.Ed thesis.

Warwick, D. P., \& Reimers, F. (1995). Hope or despair. Learning in Pakistan's primary schools. Westport, CT: PRAEGER.

Wheeler,A. E. (2000). Reconceptualising teacher education: An experience from Pakistan. Canadian and International Education, 29(2), 69-88. 